University of South Florida

DIGITAL COMMONS

Digital Commons @ University of

@ UNIVERSITY OF SOUTH FLORIDA

South Florida

QMaSC: A Handbook for Directors of

Quantitative and Mathematics Support Centers

USF Libraries

$1-1-2016$

\title{
12. Virtual Presence
}

McKayla Nuffer

St. Lawrence University

Follow this and additional works at: https://digitalcommons.usf.edu/qmasc_handbook

\section{Recommended Citation}

McKayla Nuffer (2016), "Virtual Presence", http://dx.doi.org/10.5038/9780977674435.ch12 in G.

Coulombe, M. O'Neill, M. Schuckers (Eds.) A Handbook for Directors of Quantitative and Mathematical

Support Centers, Neck Quill Press, http://scholarcommons.usf.edu/qmasc_handbook.

This Community Interactions is brought to you for free and open access by the USF Libraries at Digital Commons @ University of South Florida. It has been accepted for inclusion in QMaSC: A Handbook for Directors of Quantitative and Mathematics Support Centers by an authorized administrator of Digital Commons @ University of South Florida. For more information, please contact digitalcommons@usf.edu. 


\section{Virtual Presence}

(C) McKayla Nuffer,

St. Lawrence University

吅

\section{Introduction}

Computers and information technologies have been a growing interest throughout society and, particularly, the area of education over the past fifty years. Modern, high-speed computers, and, more specifically, instant access to the internet, produces a dependency within the global economy and scientific age in which we live. The launch of Sputnik in 1957 prompted national efforts to reform education with new technological practices and an improved philosophy to educate the masses [1]. Since then, the National Defense Education Act has supported educational reform and the incorporation of technology within school curricula [1]. More recently, the use of the World Wide Web has increased at a prominent rate and become responsible for the success of businesses, organizations, and educational institutions.

Access to information and services through the "click of a button" is appealing to many, specifically college students. Students find comfort in accessing assistance and academic support at their convenience outside of the classroom, especially during late night cram sessions before quizzes and exams. A quantitative and mathematics support center (QMaSC) provides services and information to students that will aid the progression in their studies, and QMaSCs aim to provide quality assistance in a convenient manner. In addition to its physical location, a QMaSC must also be virtually present in meeting the needs of students. This chapter addresses how to be virtually

Suggested Citation: McKayla Nuffer (2016), "Virtual Presence", http://dx.doi.org/10.5038/9780977674435. ch12 in G. Coulombe, M. O'Neill, M. Schuckers (Eds.) A Handbook for Directors of Quantitative and Mathematical Support Centers, Neck Quill Press, http://scholarcommons.usf.edu/qmasc_handbook.

This material is based upon work supported, in part, by the National Science Foundation under Grant DUE1255945. Any opinions, findings, and conclusions or recommendations expressed in this material are those of the author(s) and do not necessarily reflect the views of the National Science Foundation 
present and the kinds of information and services to provide virtually in order to market effectively the services provided by the center.

\section{What is Virtual Presence?}

Before deciding what to include on a center's website or what devices to use to become virtually present as a center, one should know what it means to be virtually present. According to Heiner Wolf (2005), virtual presence is about mutual awareness and synchronous communication on the web [2]. An individual can be virtually present at a specific web location, but virtual presence on the World Wide Web can range from viewing a website to being present in an artificial 3D space. Differing from tele-presence, virtual presence does not result in looking into real world settings, but only artificial space [2]. These types of "presences" are linked because 3D models of realistic space can be captured artificially and transferred into virtual representation [2]. Tele-presence and virtual presence can be used jointly to create options for students to seek the maximum assistance, fully demonstrating all that the web has to offer.

Given the prevalent internet usage, specifically social media - email, Facebook, Twitter, Instagram, Skype, iChat, or Google+ Hangouts - as part of everyday life, the QMaSC's ability to be virtually present is critical for public access to resources. Allowing on-the-go users access to information, updates, and course-related materials from portable devices such as laptops, smart phones, or tablets enhances the center's ability to serve more students. Acting as a catalyst for academic growth and support is rewarding for a center. The implementation of a website and other virtual systems will often increase student engagement in using resources, thereby allowing the center to act as a catalyst for academic growth and support.

Many different types of services and tools are offered within the realms of virtual and telepresence. Tools that can be incorporated into the center's website to supply students with as many virtual resources as possible include social networking forums, such as Facebook, Twitter, and personal blogs, or online tutoring and direct communication forums, such as wikis, Skype, iChat, Microsoft Lync, Lynda.com, video streaming, YouTube videos, and eBeam. Successful sites often include links to data and software resources. Likewise, learning management systems, known as virtual learning environments (VLEs), can provide virtual assistance and tutoring to students through the posting of course syllabi, course materials, and texts, in addition to discussion forums for the courses supported by the QMaSC. Popular VLEs include Moodle, Sakai, Angel, Blackboard, Claroline, and ATutor; any of these can serve as an additional resource that can be developed outside of the standard website [3]. Directors can learn more about these tools by talking to other QMaSC directors, talking with the information technology departments at the parent institution, or by additional online research. Ultimately, all of these virtual tools, organized through the creation of a website, will enhance the virtual presence of the center. 


\section{Beginning a Center Website}

While many avenues exist in beginning to develop a website, the most common, and strongly encouraged, path is to contact your institution's information technology and web services department. Most institutions enforce policies regarding the use and public access of institutional computing resources and the campus network. At some institutions, these departments issue strict guidelines and standards for the creation of webpages. Standards may be stylistic in nature governing color, font selection and size, or guidelines may concern content such as hyperlinks, text, images, and navigation.

At St. Lawrence University, standards are established for all webpages for academic and administrative departments addressing required links, required content, and limits on design. Examples of these guidelines include the following instructions: "have a link to the St. Lawrence homepage on them," "have your department or section name on them," and "avoid using varied design elements, such as different background colors or fonts on different pages" [4].

Not all directors actively create the center website but many, if not all, supply the content for and assist in developing the ideas for the website. By contrast, some directors create the entire website under the review and guidance of a web team. It is essential for directors to understand the various processes and procedures required by the information technology and web services department; therefore, directors must start by setting up meetings with the appropriate departments and offices.

Building a website involves a number of major decisions, four of which include: choosing the type of website, selecting a web host, establishing a domain, and identifying and designing key features for the website. In turn, these decisions influence future decisions such as content, design, organization, and additional features that make a user-friendly website. For those who will build a web site from the ground up, and those without guidelines mandated by their institution, sections $4-6$ address guidelines for the first steps in creating a web site. For those with institutionally mandated guidelines, much of the discussion in sections $4-6$ will be handled completely by the web services department or in partnership with that department.

\section{Static vs. Dynamic Websites}

For directors creating a website from scratch, the first step is deciding on the desired type of website: static or dynamic. Static websites have "content embedded in HTML code" while "the content and layout [are moderately] independent" [5]. There are no special requirements on the web host (see section 5 on web hosts) and entering content involves writing HTML code, this is similar to computer programming [5]. Static HTML is used to display pages with no comments, blogs, daily additions, or special features that require advanced functionality [6]. The files are loaded, then the browser retrieves and displays images, item links, video, and other materials. Static websites 
effectively establish a center's virtual presence because they are clean, secure, load quickly, and are easy to manage [6].

In comparison, dynamic websites allow content to be retrieved from a database, and content can be arranged by date, category, or similar organizational structures. Dynamic websites are ideal for blogs or chronological entries. The content and layout of dynamic websites are independent, and entering content is similar to word processing. Dynamic websites present a desirable alternative for those unfamiliar with writing HTML [5]. Dynamic websites are also popular because social media, surveys, and feedback are easily integrated into the pages; this allows centers to have both a virtual and a tele-presence. The advanced functionality of dynamic websites allows direct interaction between the creator and the user; however, dynamic sites are slower to load and more expensive than static websites [7, 6].

Both types of websites are suitable for a QMaSC, but the choice depends on the creator's willingness and time, knowledge of and skill level with the different content management systems or existing website building systems possibly supported by the parent institution, and the associated institutional constraints and support.

\section{Choosing a Web Host}

After selecting the type of site to be designed, choosing a host is the next, and most crucial, step. Knowledge and skill come into play because many different types of web building systems exist that are crafted for either the static or the dynamic website. Those building a website from scratch or those under the assistance of a web services team must select a host compatible with the institution's server, this ensures the website's approval and associated support of the university communications and public relations office.

Manually setting up a host requires the knowledge of code and script and requires special web design software [6]. Such website creators must know how to code and save files in HTML and how to use cascading style sheets (css) which maintain consistency of fonts, colors, and styles throughout the website [5]. While manual web hosts provide templates, knowledge of HTML coding is essential to enable the page creator flexibility in customization. Both Dreamweaver and Joomla, tools for setting up manually created sites, require the knowledge of HTML code content management systems to organize and create static (Dreamweaver) or dynamic (Joomla) websites.

Using Dreamweaver enables creators to design pages that exhibit pictures of staff, schedules and other documents in PDF format, links to other websites and data search engines, among other features. Advertisements, widgets, and other gadgets can be added to the QMaSC website using this web design software.

Joomla is ideal for building small to medium sites and is known to be fast and accessible in many places [2. The inclusion of dynamic features, such as image galleries, YouTube videos, guest books, 
polls, calendars, file managers, and forms [2], combine multimedia, communication, collaboration, and data management all within the center's website.

Other mechanisms exist for manually creating a website, many are designed to use preexisting templates and style options for creating customized work with little to no experience in either coding or programming. Artisteer and WordPress are web hosts that create both static and dynamic websites. The features they provide make the process of creating and organizing content easier and more user-friendly [6]. With Artisteer, coding can be used to edit and customize a site, but be advised that the learning curve is steep [5]!

Google Sites provide another web hosting option requiring no coding knowledge. Unlike the aforementioned web hosts, Google Sites is free. Google Sites users need only have a Google account in order to create pages using the website templates. Other free options exist for hosting but most carry the risk of losing your entire site at the will of the web host. To ensure this does not happen, choose a host so that the center URL does not include the host name - a free web host gains publicity by including its name in the domain name of its patrons. Google Sites provide a safe and free option for centers with limited funds for producing a website.

\section{Establishing a Domain}

The selected web host influences the last step, establishing a web domain, in preparation of designing the website. Establishing a domain is the same as identifying a web address for your site. Registering a domain involves serious thought and consideration, despite seeming like a minor task in the creation of a website. While determining a name for the site may at first appear to be an elementary task, there are many ways to go about deciding a web address.

In naming the website, consider both the future QMaSC users and the keywords that best describe the center. Because the web address will be frequently advertised and used continually, it should be catchy and appealing to the user. Consider the length and characters within the domain. Avoid discouraging users by using a long address or one that is embellished with varying capitalization, numbers, or symbols [6]. Finally, avoid using any preexisting trademarks or names that may inadvertently lead a user to the wrong website [6]. (A name that is closely related to another website may discourage users who have difficulty locating the site and may eventually require a major and costly name change.) Hence, initial research into the possible domain names for ease of use and uniqueness will be worth the effort.

These three steps form the necessary preparation for the more enjoyable aspect of creating a website: design and organization. As previously stated, most of these steps are typically mandated by your institution, but having the background knowledge in what it takes to create a website can help directors when assisting a web team. Once a domain and a web host have been established, the focus shifts to content and features. 


\section{Recommended Features for Websites}

Each center is managed and run in its own particular manner, but those commonalities in services that most centers provide for students should be displayed on the website. Whether the page employs hyperlinks, text, images, or PDF files, the content and material described below can be included to enhance to the center's virtual presence.

\section{General Information and the Home Page}

General information about the center, including the mission statement, brief history, and overview of services are possible items for display within the site. The overview can identify the courses that are supported by the center and may be accompanied by the names of professors and instructors for the courses; however, more general descriptions are more practical because maintaining updates for this level of detail is time consuming. Typically, general information is located on the "Home" page or an "About" page that can lure users into reading further and sets the stage for what the entire website and center have to offer. The home page should contain an opening message, welcoming and inviting users to continue reading the website.

The "Home" page is often the first space that users see, so the selection of user-friendly colors and fonts is crucial for this visual representation of your center. Web page creators should choose a color scheme that is cohesive and complementary if the color scheme is not mandated by the center's parent institution. Maintaining stylistic consistency throughout the site is critical; for example, make headers, text, and links follow a set color scheme. Not only will this make the site look professional but will help users in recognizing key features and information through color coordination. Likewise, avoid fancy, cursive or symbolic fonts. Font should be sized large enough so that all viewers are able to read the page. Always think from the professional and student perspectives when deciding on the aesthetic style of the website. Make it "eye-popping" and clear. Unless the site is visually stimulating and simple, users may not see all the details. Attractive and inviting pictures of the center help students become virtually familiar with the space and welcome the users to visit the center.

\section{Tutor and Staff Directories}

Before receiving or considering services, students and faculty appreciate a clear and pictorial directory of mentors, tutors, directors, assistant directors, and other personnel. This offers users a sense of comfort and familiarity for they already have a name, picture, or both to refer to upon entering the center. Many sites have "Staff" or "People" pages which group the staff based upon their roles within the center. A possible design format for the directory entry for a mentor or tutor might include his or her name, class year, major(s), minor(s), course support, software support, and photo. Similarly, the site might contain short biographical blurbs for each of the directors and 
other staff members of the QMaSC.

\section{Expectations and FAQ Pages}

Informative pages often include a description of what to expect from a tutoring session or other services. Such information can be discussed and organized in more than one way. For example, on the website for the Peterson Quantitative Resource Center at St. Lawrence University, two pages provide information on: "What to Expect" and "What Not to Expect" when coming to the center. Having both pages clearly distinguishes the expectations and definition of a standard mentoring session, which explains what mentors do for students and gives a clear definition of the mentor's role in assisting students. Such concerns may also be addressed on a "FAQ" (Frequently Asked Questions) page. FAQs often provide descriptions of a typical tutoring session, directions for entering the center, the location of the center, and how to contact a tutor for individual sessions.

\section{Schedules}

Hours of operation and appropriate schedules should be posted on the website. These can be attached as PDF files, Excel spreadsheets, or presented in a table. Centers may have multiple schedules for a variety of services, but the most important schedule is often the drop-in tutoring schedule. At any given time, students might want to access information about when specific tutors are working. Similarly, a schedule organized around course coverage and giving a list of supported courses, along with the hours of operation for each course, is useful to students. Depending on how the center is structured, whether open hours are offered, or a specific set of hours is set aside for certain courses, providing schedules is vital information to be displayed on the website.

\section{Attendance Tracking}

Directors need to keep track of the flow of traffic in and out of the QMaSC for data collection purposes. Some center websites include a log-in page. This can be accomplished by using a commercially packaged attendance tracker or by developing an in house system using a database. Regardless of the method used, directors can manage and gather data for their own personal records or, at any given time, present statistics and figures to faculty and administrators. Demographic data about students can be gathered by requesting the following information at login: name, class year, whether this is a first time visit to the center (newly opened centers might want to ask how the visitor first learned about the center), the course for which assistance is sought (this may vary depending on the center's services), and other pertinent information sought for tracking purposes. Check with the Registrar's Office or Dean's Office regarding FERPA laws related to data collection and use. Some institutions allow students to use services confidentially or have students check a box stating that the data can be shared with administrators and faculty. If clearance is given, the resulting login statistics may be useful to faculty or an advisory board. 
Similarly, a tutorial report form and tutor evaluation form can also be established to help monitor the activities and performance of a tutor. Because the primary goal of a resource center is to meet the needs of the students through providing quality services, satisfaction surveys can be used to seek information on the quality of the overall session, the tutor's presentation, and additional comments. This feedback will help in addressing major concerns of the students through improvements that can be made. Online surveys are always available to visitors whether completed on site or online after students leave the center. The surveys can be easily generated using the attendance tracking systems, Google forms, Qualtrics surveys, or other online forms. In this way, the virtual presence of the center helps to monitor the success and perception of the center.

\section{Use of Social Media}

The popularity of social media suggests that methods for students to contact and communicate with the center is an important area of focus. According to Eric Chapman (2011), "between 85 percent and 99 percent of college students use Facebook ... [and] students spend an average of 106 minutes on Facebook per day" [8]. University and college admission programs use social media to contact students and provide information and materials to prospective students at low costs through Facebook, Twitter, and YouTube. The use of such platforms is advantageous to a QMaSC in reaching students through these heavily utilized media. Centers can use social media sites to deliver efficient updates and important messages to students about upcoming exams, tutorials offered by the center, and changes in hours of operation and scheduling. Depending on the chosen web host, calendar attachments and templates can be used and easily adapted to meet the needs of the QMaSC in addressing similar updates to students or through certain email accounts, such as Gmail and Microsoft Outlook (Google's calendar template can be attached directly to the center's site when Google Sites is used as the web host). Some colleges or universities use course-management systems (CMS) such as Moodle, Blackboard, or Sakai. Directors may wish to set up a page on the institutionally supported CMS site to manage tutors or establish "sub-boards," a forum-type interface, for updating students. Center mentors and staff can form a Facebook group in which members can post a status in order to find a sub for a given drop-in shift and respondents can post a comment when they are able to take the open shift. Similarly, listservs or email groups also meet this need.

Mixed reviews exist on whether to use social media for the purposes of finding tutor/mentor coverage, networking, and supplying students information and updates on the website. In a recent roundtable discussion, some directors argued that these areas were already being addressed without the need of social media [9]. Some tried it and then deleted the social media accounts because they duplicated what they were already doing on their main website [9]. While placing information in more than one area is not necessarily excessive, maintaining multiple virtual forums can get complicated. Conversely, placing an advertisement in multiple forums gives more visibility and may 
result in more patrons coming to the center. Being mindful of particular student populations and how they communicate can help determine where information is placed and assist in making the necessary choices to become virtually present.

\section{External Resources}

Because tutors and mentors cannot staff drop-in hours 24 hours per day, providing students with web access to extended resources such as web addresses for scholarly research, data search engines, video tutorials, fact sheets, or other materials expands the effectiveness of the center beyond the physical services of the QMaSC staff. Students will appreciate the time and energy used to create these resources and will be more receptive and willing to explore what these pages offer. Outside online resources can disappear or change, so it is important to regularly manage and verify links to ensure they continue to offer appropriate resources.

Beyond providing links and other preassembled resources, directors can post the same help sheets that are provided at the center or distributed during workshops or tutorials throughout the year. Segmented video recordings of workshops can also be posted for students to view at their convenience. While this may reduce the number of students who visit the center or attend workshops, it provides students with alternate options for getting help. Some students prefer to work with an actual person rather than looking at a worksheet, but those who are fearful of using services will appreciate the online option. Most students like having multiple options such as working with others when they are having difficulty understanding a concept, taking the personal instructional route, seeking assistance of the center's staff, and using the online resources for quick references.

Placing these resources on the QMaSC website, coupled with previously mentioned components, creates a strong virtual presence for the center. Other possible additions to the site include applications for becoming a tutor, links to all departments supported by the center, YouTube videos for tutor training, pictures of the center, photo albums of events, and more. Depending on factors such as the availability of the center's staff for specific courses, the hours of operation, and the size of institution, online tutoring options that use virtual whiteboards and other commercially developed, or free, systems are alternative components for meeting student needs.

\section{Conclusion}

Being virtually present and building a website is a progressive route any QMaSC director can employ. Many technologies are used within education. Knowing and continuing to seek assistance from other centers and experts, within the education and technological fields, will aid directors in providing the best support opportunities for eager students. Because many colleges and universities have a quantitative or mathematical literacy requirement for graduation, more and more students 
will need assistance. QMaSCs can guide the way! As computers, tablets, and other portable devices become more prevalent, assembling virtual locations for students to access the skills, knowledge, and materials designed to meet their academic needs becomes essential. The QMaSC website can showcase the work and assistance provided to the future mathematicians, scientists, engineers, professionals, and humanities students of the world. Become virtually present and join the information age, because no one wants to "byte" the dust! 


\section{Bibliography}

[1] A. Molnar, "Computers in education: A brief history," The Journal, 1997. Accessed from http: //thejournal.com/Articles/1997/06/01/Computers-in-Education-A-Brief-History. aspx?Page=1 on March 14, 2013.

[2] H. Wolf, "Home page." Accessed from http://www.virtual-presence.org on June 6, 2013.

[3] I. Clement, "Virtual learning environment comparison," 2003. Accessed from http://atutor. ca/atutor/files/VLE_comparison.pdf on September 8, 2013.

[4] St.Lawrence University, "Website standards." Accessed from http://www.stlawu.edu/ university-communications/website-standards on September 9, 2013.

[5] T. Siegers, "Building Dynamic Websites with Joomla CMS," 2010. Accessed from http:// WWW.slideshare.net/thomasjs/building-dynamic-websites-with-joomla-cms on June 5, 2013.

[6] L. Irby, "Homepage," 2013. Accessed from http://www.2createawebsite.com/ on June 2, 2013.

[7] A. Fenton, "Static vs. Dynamic Websites — What is the Difference?," 2013. Accessed from www.edinteractive.co.uk/article/?id=4 on June 3, 2013.

[8] E. Chapman, "Facebook facts revealed," November 2011. Accessed from http://www. collegiatetimes.com/stories/18784/facebook-facts-revealed on June 11, 2013.

[9] P. Conrath, "Notes taken at St. Olaf Round Table on Academic Support," 2013. 